\title{
Risk factors and preventive measures for C5 palsy after cervical open-door laminoplasty
}

\author{
Hideaki Nakajima, MD, PhD, Hiroyuki Kuroda, Shuji Watanabe, MD, PhD, Kazuya Honjoh, MD, and \\ Akihiko Matsumine, MD, PhD
}

\begin{abstract}
Department of Orthopaedics and Rehabilitation Medicine, Faculty of Medical Sciences, University of Fukui, Eiheiji-cho, Yoshida-gun, Fukui, Japan
\end{abstract}

\begin{abstract}
OBJECTIVE The pathomechanism of C5 palsy after cervical open-door laminoplasty is unknown despite the relatively common occurrence of this condition postoperatively. The aim of this study was to review clinical and imaging findings in patients with $\mathrm{C} 5$ palsy and to propose countermeasures for prevention of this complication.

METHODS Between 2001 and 2018, 326 patients with cervical myelopathy underwent cervical laminoplasty at the authors' hospital, $10(3.1 \%)$ of whom developed C5 palsy. Clinical features and radiological findings of patients with and without $\mathrm{C} 5$ palsy were analyzed.

RESULTS In patients with C5 palsy, the width of the C5 intervertebral foramen was narrower and the position of the bony gutter was wider beyond the medial part of the $C 5$ facet joint. The distance between the lateral side of the spinal cord and bony gutter was significantly greater in patients with C5 palsy. Patient characteristics, disease, cervical alignment, spinal canal expansion rate, anterior protrusion of the $\mathrm{C5}$ superior articular process, high-intensity area in the spinal cord on T2-weighted MR images, posterior shift of the spinal cord, and operative time did not differ significantly between patients with and without $\mathrm{C} 5$ palsy.
\end{abstract}

CONCLUSIONS The position of the bony gutter may have a central role in the pathomechanism of postoperative C5 palsy, especially in patients with a narrow $\mathrm{C} 5$ intervertebral foramen. Making an excessively lateral bony gutter might be a cause of $\mathrm{C} 5$ nerve root kinking at the intervertebral foramen. To prevent the occurrence of $\mathrm{C} 5$ palsy, it is important to confirm the medial line of the facet joint on the preoperative CT scan, and a high-speed burr should be started from inside of the facet joint and manipulated in a direction that allows the ligamentum flavum to be identified.

https://thejns.org/doi/abs/10.3171/2019.10.SPINE19993

KEYWORDS laminoplasty; cervical spine; C5 palsy; postoperative complication; risk factor; clinical outcome

$\mathrm{T}$ HE number of patients needing surgery for progressive myelopathy of the cervical spinal cord has increased proportionately with the increasing age of the population. Cervical laminoplasty is an effective procedure with few complications and is currently widely used as the main surgery for cervical compressive myelopathy. ${ }^{4,30}$ However, postoperative C5 palsy remains as a serious complication, and affected patients have muscle weakness, brachialgia, and numbness and are dissatisfied with their surgery. ${ }^{6}$ A previous review characterized the features of C5 palsy as follows: 1) 50\% of patients have accompanying sensory disturbance or intolerable pain in the C5 region; 2) $92 \%$ of patients have hemilateral palsy; 3) almost all palsy appears within a week after surgery; and 4) the prognosis is relatively good, but patients with severe paralysis require longer recovery times. ${ }^{22} \mathrm{~A}$ meta-analysis showed the prevalence of C5 palsy to be $5.1 \%$ after cervical laminoplasty without fusion. ${ }^{25}$ Despite postoperative C5 palsy being relatively common, the pathomechanism is unknown, but it may involve segmental spinal cord disorder, nerve root injury, and iatrogenic heat injury due to the use of an air drill. ${ }^{9}$ The aim of this retrospective study was to review clinical and imaging findings in patients with C5 palsy after cervical laminoplasty and to propose countermeasures for the prevention of this complication.

\section{Methods \\ Study Population}

Between 2001 and 2018, a total of 326 consecutive patients with cervical myelopathy underwent cervical opendoor laminoplasty at our hospital. The procedure was per-

ABBREVIATIONS CSM = cervical spondylotic myelopathy; JOA = Japanese Orthopaedic Association; OPLL = ossification of the posterior longitudinal ligament. SUBMITTED August 24, 2019. ACCEPTED October 22, 2019.

INCLUDE WHEN CITING Published online December 20, 2019; DOI: 10.3171/2019.10.SPINE19993. 
TABLE 1. Patients with and without C5 palsy after cervical open-door laminoplasty

\begin{tabular}{|c|c|c|c|c|}
\hline \multirow[b]{2}{*}{ Item } & \multirow[b]{2}{*}{$\begin{array}{l}\text { C5 Palsy } \\
\text { (group P) }\end{array}$} & \multicolumn{2}{|c|}{ No C5 Palsy } & \multirow[b]{2}{*}{$\begin{array}{c}p \\
\text { Value* }\end{array}$} \\
\hline & & All & $\begin{array}{l}\text { Selected } \\
\text { (group N) }\end{array}$ & \\
\hline No. of patients (\%) & $10(3.1)$ & 316 & 40 & NS \\
\hline Mean age, yrs & $69.8 \pm 9.6$ & $69.8 \pm 9.7$ & $69.9 \pm 9.8$ & NS \\
\hline \multicolumn{5}{|l|}{ Diseases } \\
\hline $\operatorname{CSM}(\%)$ & $7(3.3)$ & 215 & 28 & \multirow{2}{*}{ NS } \\
\hline OPLL (\%) & $3(2.7)$ & 111 & 12 & \\
\hline Mean preop JOA score & $11.6 \pm 1.5$ & $11.4 \pm 2.6$ & $11.3 \pm 2.7$ & NS \\
\hline
\end{tabular}

NS = not significant.

Data are presented as the number (\%) of patients or mean \pm SD.

${ }^{*} p$ values for patients with $C 5$ palsy versus control group.

formed using Itoh and Tsuji's method. ${ }^{12}$ The open side of the lamina was lifted and affixed with the cervical spinous process or plate. All patients exhibited clinical signs and symptoms of myelopathy. Patients with coexisting cervical trauma, rheumatoid arthritis, destructive spondyloarthritis, and cervical spondylotic amyotrophy were not included in this study. The study protocol was approved by the Human Ethics Review Committee of our university medical faculty and strictly followed the Clinical Research Guidelines of the Ministry of Health, Labour and Welfare of the Japanese government.

C5 palsy was defined as a grade of $\leq 3$ on a deltoid manual muscle test conducted within 2 weeks after surgery, with or without involvement of the biceps. Among the patients, $10(3.1 \%)$ with C5 palsy (group P) were identified in this study. To compare imaging findings of these patients with those from patients without C5 palsy, a control group of 40 patients (group $\mathrm{N}$ ) was selected from the 316 patients without C5 palsy, with consideration of age, sex, underlying diseases, and preoperative Japanese Orthopaedic Association (JOA) scores. All patients in groups $\mathrm{P}$ and $\mathrm{N}$ underwent plain radiography, $\mathrm{CT}$ scanning ( $\leq 2$ $\mathrm{mm}$ in slice thickness), and 1.5- or 3.0-T high-resolution MRI (Signa) before and after surgery (Table 1).

\section{Outcome and Radiological Measurements}

Neurological assessment was based on the JOA score for cervical myelopathy. ${ }^{30}$ The rate of neurological improvement at 1 year after surgery was calculated as follows: [(postoperative follow-up JOA score - preoperative JOA score $) /(17$ - preoperative JOA score $) \times 100]$.

Radiological studies comprised plain cervical radiographs, CT scans, and high-resolution MRI (1.5- or 3.0-T Signa) studies (Fig. 1). On plain radiographs, the cervical lordotic angle $(\theta)$ in a neutral position and spinal canal expansion (\%) were assessed (Fig. 1A). On axial CT scans, the width of the intervertebral foramen at C5 (narrowest point on the open side), the anterior protrusion of the superior articular process of C5 (most prominent line: c), and position of the bony gutter were assessed using modifications of published methods. ${ }^{11}$ The bony gutter position was expressed as the ratio of the distance between the midline

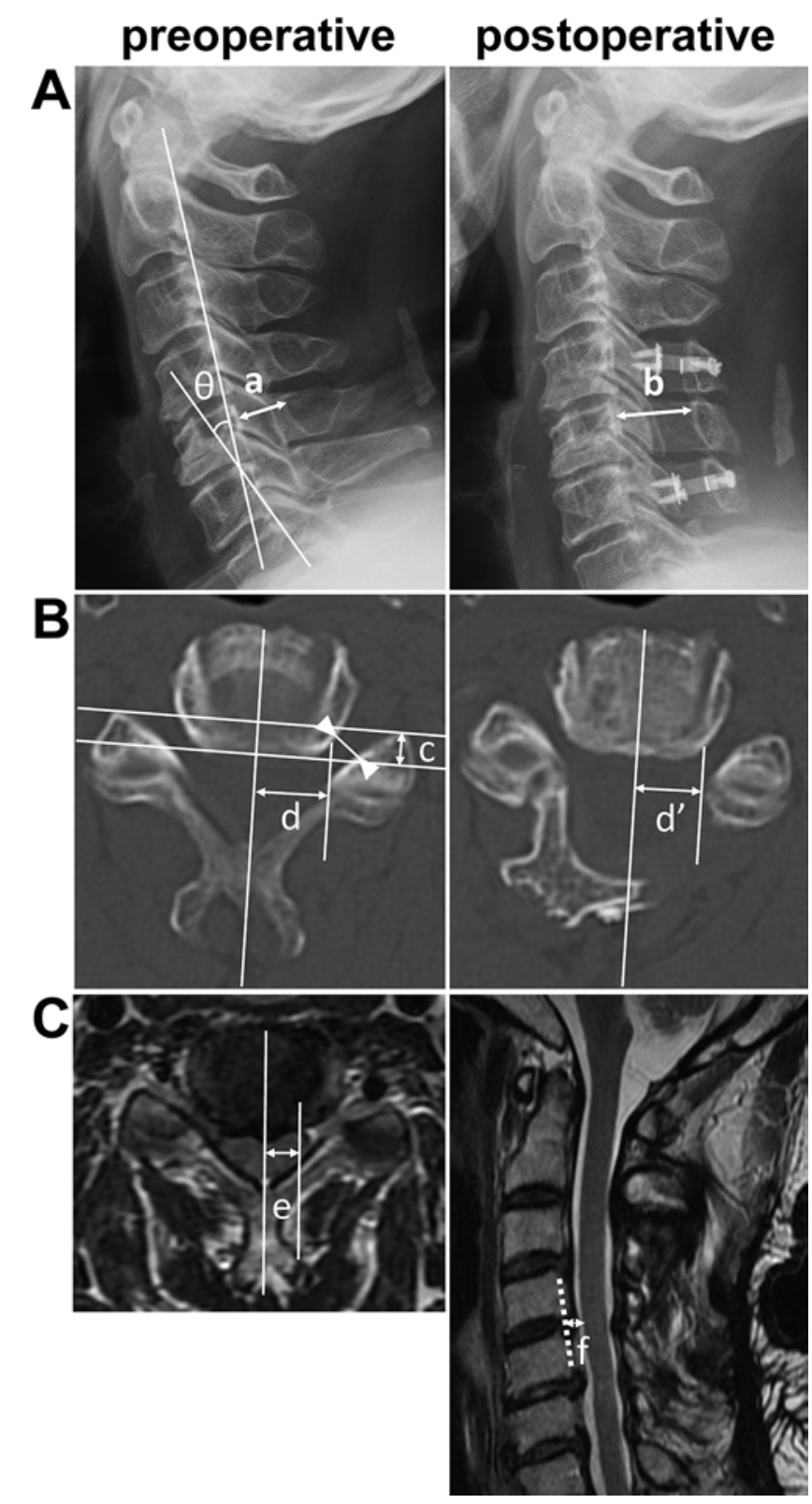

FIG. 1. Radiological measurements. A: Assessment on plain radiographs. The preoperative $\mathrm{C} 2-7$ lordotic angle $(\theta)$ was measured between the tangential lines along the posterior borders of the $\mathrm{C} 2$ and $\mathrm{C} 7$ vertebral bodies. The spinal canal expansion rate (\%) was defined as the postoperative (double-headed arrow, b) divided by preoperative (double-headed arrow, a) anteroposterior diameter of the bony spinal canal at the C5 level. B: Assessment on CT scans. The width of the intervertebral foramen at C5 was measured at the narrowest point (distance between arrowheads). The anterior protrusion of the C5 superior articular process was measured at the most prominent line (double-headed arrow, c). The position of the bony gutter was defined as the postoperative distance between the midline of the $\mathrm{C} 5$ vertebral column and the medial point of the gutter (double-headed arrow, $\mathrm{d}^{\prime}$ ) divided by the preoperative distance to the most medial part of the facet joint (double-headed arrow, d) (\%). C: Assessment on T2-weighted MRI studies. The preoperative width of the spinal cord at $\mathrm{C} 5$ was defined as the distance between the midline of the $\mathrm{C} 5$ vertebral column and the lateral point of the spinal cord (double-headed arrow, e). The posterior shift of the spinal cord at C4-5 was defined as the postoperative distance between the cephalocaudal midpoint of the posterior margin of the C4-5 disc (dotted line) and the nearest point of the anterior margin of the spinal cord (double-headed arrow, $\mathrm{f}$ ). 
TABLE 2. Imaging results for the C5 palsy and control groups

\begin{tabular}{|c|c|c|c|}
\hline Imaging Modality & $\begin{array}{c}\text { C5 Palsy } \\
\text { (group P; } n=10 \text { ) }\end{array}$ & $\begin{array}{c}\text { No C5 Palsy } \\
\text { (group N; } n=40 \text { ) }\end{array}$ & p Value \\
\hline \multicolumn{4}{|l|}{ Plain radiography } \\
\hline C2-7 angle & $13.6^{\circ} \pm 6.1^{\circ}$ & $17.4^{\circ} \pm 10.2^{\circ}$ & 0.158 \\
\hline Spinal canal expansion rate, $\%$ & $157.3 \pm 20.6$ & $152.8 \pm 18.2$ & 0.557 \\
\hline \multicolumn{4}{|l|}{ CT } \\
\hline Width of C5 intervertebral foramen (open side), $\mathrm{mm}$ & $2.1 \pm 0.3$ & $3.3 \pm 1.1$ & $<0.01^{*}$ \\
\hline Anterior protrusion of $\mathrm{C} 5$ superior articular process, $\mathrm{mm}$ & $5.1 \pm 2.6$ & $5.3 \pm 2.1$ & 0.821 \\
\hline Position of the bony gutter, $\%$ & $103.2 \pm 6.4$ & $85.4 \pm 9.7$ & $<0.01^{*}$ \\
\hline \multicolumn{4}{|l|}{ MRI } \\
\hline High-intensity area in the spinal cord on T2-weighted images, no. (\%) & $7(70.0)$ & $30(75.0)$ & 0.747 \\
\hline Posterior shift of the spinal cord (C4-5), mm & $4.3 \pm 1.5$ & $4.2 \pm 1.5$ & 0.943 \\
\hline Distance from lateral side of spinal cord to bony gutter (C4-5), mm & $4.7 \pm 0.8$ & $2.6 \pm 1.1$ & $<0.01^{*}$ \\
\hline
\end{tabular}

Data are shown as the number $(\%)$ of patients or mean \pm SD.

${ }^{*}$ Significant difference $(p<0.05)$.

of the vertebral column at $\mathrm{C} 5$ and the medial point of the gutter on postoperative CT scans $\left(\mathrm{d}^{\prime}\right)$ relative to the distance between the midline of the vertebral column at C5 and the most medial part of the facet joint on preoperative CT (d) (Fig. 1B). On axial and sagittal MRI studies, the presence of a high-intensity area in the spinal cord on T2-weighted images preoperatively, the width of the spinal cord (e), and the postoperative posterior shift of the spinal cord (f) (Fig. 1C) were assessed, again with modified published methods. ${ }^{11,20}$ The distance between the lateral side of the spinal cord and bony gutter (C4-5) was calculated (d' - e [mm]). All measurements were performed in triplicate by each of two observers, and the average value was used.

\section{Statistical Analysis}

Data are expressed as mean \pm SD. Intergroup differences were examined using the Wilcoxon signed-rank test, Mann-Whitney U-test, or chi-square test. A p value $<0.05$ denoted significance. Inter- and intraobserver reliabilities were assessed using intraclass correlation coefficients. These statistical analyses were conducted using SPSS software (version 24.0, IBM Corp.). Power analysis was performed with EZR (Saitama Medical Center), ${ }^{13}$ which is a graphic user interface for R (The R Foundation for Statistical Computing).

\section{Results}

\section{Demographics of Patients}

Demographic data for patients with and without C5 palsy are shown in Table 1. Of 326 patients who underwent cervical open-door laminoplasty, 10 (3.1\%) developed C5 palsy, and all paralysis occurred on the open side. The mean age of these 10 patients at the time of surgery was $69.8 \pm 9.6$ years, and 7 had cervical spondylotic myelopathy (CSM), and 3 had ossification of the posterior longitudinal ligament (OPLL). The mean JOA score before surgery was $11.6 \pm 1.5$. There were no significant differences in background characteristics, disease, and preoperative neurological scores between the group with (group P) and without (group N) C5 palsy. There was also no difference in the prevalence of C5 palsy between patients with CSM (7/215: $3.3 \%)$ and patients with OPLL (3/111: $2.7 \%)(\mathrm{p}=$ $0.784)$.

\section{Clinical and Radiological Outcomes}

The results of imaging in the group with (group P) and without (group N) C5 palsy are shown in Table 2. The sample size of group P $(n=10)$ had sufficient statistical power to allow comparison between the two groups ( $p$ $=0.05$, power $=0.80$ ). On plain radiographs, the average C2-7 lordotic angle of the cervical spine was similar in patients in groups $\mathrm{P}$ and $\mathrm{N}\left(13.6^{\circ} \pm 6.1^{\circ}\right.$ and $17.4^{\circ} \pm 10.2^{\circ}$; $\mathrm{p}=0.158)$. There was no significant difference in spinal canal expansion between the respective groups $(157.3 \% \pm$ $20.6 \%$ vs $152.8 \% \pm 18.2 \%$; $=0.557$ ). On CT scans, the mean C5 intervertebral foramen width on the open side was significantly lower in group P than group $\mathrm{N}$ (2.1 vs $3.3 \mathrm{~mm}$; $<<0.01$, power $=0.893$ ), and the mean position of the bony gutter differed significantly between the groups $(103.2 \%$ vs $85.4 \%$, respectively; $p<0.01$, power $=0.994)$. All patients in group P had a C5 intervertebral foramen $\leq$ $2.6 \mathrm{~mm}$ and a position of the bony gutter $\geq 100 \%$. In contrast, 14 patients (35.0\%) in group $\mathrm{N}$ had an intervertebral foramen $\leq 2.6 \mathrm{~mm}$, and no patients had a position of the bony gutter $\geq 100 \%$. There was no difference in anterior protrusion of the C5 superior articular process in the two groups $(\mathrm{p}=0.821)$. The mean distance on preoperative $\mathrm{CT}$ scans (c [Fig. 1]) between the midline of the vertebral column at $\mathrm{C} 5$ and the most medial part of the facet joint was $11.3 \pm 1.3 \mathrm{~mm}$ (Fig. 2A).

On MR images, there was no significant difference in posterior shift of the spinal cord at $\mathrm{C} 4-5$ between group $\mathrm{P}$ and group $\mathrm{N}(4.3 \pm 1.5$ vs $4.2 \pm 1.5 \mathrm{~mm}$, respectively; $\mathrm{p}$ $=0.943)$. Preoperatively, the mean spinal cord width was $6.5 \pm 0.7 \mathrm{~mm}$ (Fig. 2B), the spinal cord occupied $62.4 \pm$ $8.5 \%$ of the spinal canal, and the mean distance between the lateral side of the spinal cord and most medial part of the facet joint was $4.2 \pm 1.5 \mathrm{~mm}$ (Fig. 2C). The mean distance between the lateral side of the spinal cord and bony 


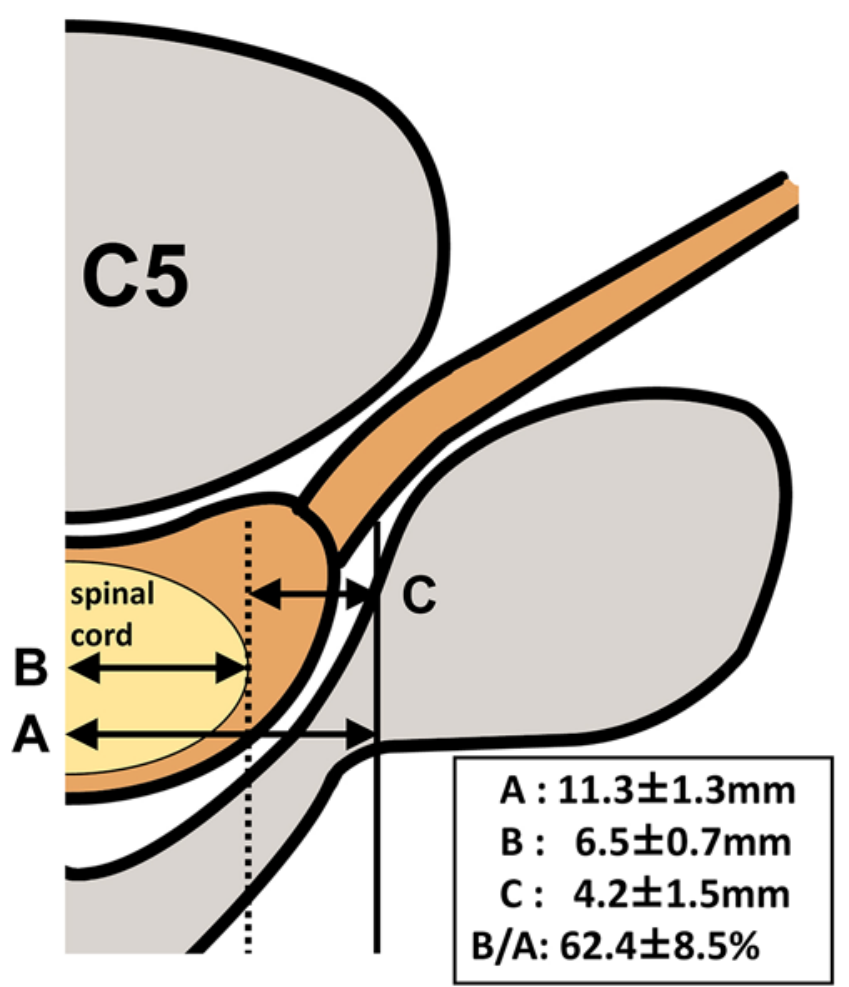

FIG. 2. Radiological assessment on preoperative CT and MRI at the C5 level. A: The mean distance between the midline of the vertebral column at $\mathrm{C} 5$ and the most medial part of the facet joint was $11.3 \pm 1.3 \mathrm{~mm}$. $B:$ The mean width of the spinal cord was $6.5 \pm 0.7 \mathrm{~mm}$. C: The mean distance between the lateral side of the spinal cord and the most medial part of the facet joint was $4.2 \pm 1.5 \mathrm{~mm}$. The spinal cord occupied 62.4 $\pm 8.5 \%(\mathrm{~B} / \mathrm{A})$ of the spinal canal. Figure is available in color online only.

gutter was significantly greater in group $\mathrm{P}$ than it was in group $\mathrm{N}$ (4.7 vs $2.6 \mathrm{~mm}$, respectively; $\mathrm{p}<0.01$, power $=$ 0.993). A high-intensity area in the spinal cord was seen at similar rates in the two groups $(7 / 10$ [70.0\%] in group $\mathrm{P}$ vs 30/40 [75.0\%] in group N). The inter- and intraobserver reliabilities for these imaging findings were both excellent $(\mathrm{p}>0.75)$.

The mean operating time was longer in group $\mathrm{P}$, but the difference was not significant $(149.9 \pm 21.8$ vs $130.0 \pm 32.4$ minutes; $p=0.07)$. There was no difference in estimated blood loss between the two groups $(p=0.25)$ (Table 3$)$.

\section{Representative Cases}

Preoperative and postoperative axial CT scans of 3 representative patients (case 1, with C5 palsy; cases 2 and 3 , controls, without C5 palsy) are shown in Fig. 3. Case 1 was an 81-year-old man with C5 palsy after surgery. The position of the bony gutter and width of C5 intervertebral foramen on the open side were $112.8 \%$ (> 100\%) and 2.2 $\mathrm{mm}$ (narrow), respectively. Case 2 was a 55-year-old man without C5 palsy. The bony gutter position was $101.8 \%$ ( $>100 \%$ ), but the width of the C5 intervertebral foramen on the open side was $3.1 \mathrm{~mm}$ (not narrow). Case 3 was a 76-year-old man without C5 palsy. The width of the C5 intervertebral foramen on the open side was $1.8 \mathrm{~mm}$ (narrow), but the bony gutter position was $83.6 \%$.
TABLE 3. Operating time and estimated blood loss in the C5 palsy and control groups

\begin{tabular}{lrrc}
\hline \multicolumn{1}{c}{ Variable } & $\begin{array}{c}\text { C5 Palsy } \\
\text { (group P) }\end{array}$ & $\begin{array}{c}\text { No C5 Palsy } \\
\text { (group N) }\end{array}$ & p Value \\
\hline Operating time, mins & $149.9 \pm 21.8$ & $130.0 \pm 32.4$ & 0.07 \\
\hline Estimated blood loss, $\mathrm{ml}$ & $61.0 \pm 41.8$ & $82.0 \pm 76.6$ & 0.25 \\
\hline
\end{tabular}

Data are presented as the mean $\pm S D$.

\section{Discussion}

Various pathomechanisms for C5 paralysis after cervical open-door laminoplasty have been proposed. In the segmental spinal cord disorder theory, the compressed cervical spinal cord may be damaged by ischemia and/ or reperfusion after surgery. This is based on the more frequent appearance on MRI of high-intensity areas at the level of the paralyzed segment in patients with postoperative paresis of the upper limb. ${ }^{5}$ However, we found no difference in the occurrence of high-intensity areas on preoperative MRI in patients with and without C5 palsy. This theory cannot explain the dominant impairment of a specific region and may be no better than diagnosis by exclusion.

The nerve root injury theory explains the features of C5 palsy well. These include sensory disturbance or intolerable pain in the $\mathrm{C} 5$ region, hemilateral palsy, with late onset, and a good prognosis. The C5 region has particular anatomical features such as the following: 1) the distance between the division from the dura mater and the exit of the foramen is shortest at the C5 nerve root; 2) the intervertebral foramen tends to be narrower at $\mathrm{C} 4$ and $\mathrm{C} 5$, in combination with a high incidence of anterior prominence of the superior facet joint; and 3) the posterior ramus proper is shortest at the C4 and C5 nerves., ${ }^{1,9,24,28,29}$ These features might lead to a "tethering effect" that stretches and compresses the C5 nerve root at the intervertebral foramen because of the gradual posterior shift of the spinal cord after decompression. ${ }^{29}$

The incidence of C5 palsy may be higher in patients with OPLL, ${ }^{7,19}$ presumably because the OPLL increases the spinal cord shift and the tethering effect on the C5 nerve root. ${ }^{3}$ In a recent meta-analysis, a similar trend was found between OPLL (5.8\%) and CSM (4.5\%). ${ }^{25}$ In our study, there was no significant difference in the prevalence of C5 palsy between CSM (3.3\%) and OPLL (2.7\%), presumably because cervical laminoplasty is not indicated for OPLL in patients with severe kyphotic deformity or a massive OPLL at our hospital; instead, anterior decompression with fusion is used..$^{18}$

The maximum posterior shift occurred at the C5 vertebral level because C5 is the apex of cervical lordosis, but most studies have found no correlation between sagittal alignment and posterior shift of the spinal cord.$^{7,8} \mathrm{We}$ also found no difference in cervical sagittal alignment in patients with C5 palsy (group P) and those without C5 palsy (group N). C5 palsy has also been suggested to be more common in cases involving a large vertebral arch opening angle and an acute hinge angle. ${ }^{7}$ It has been proposed that the lamina open angle in laminoplasty should be main- 


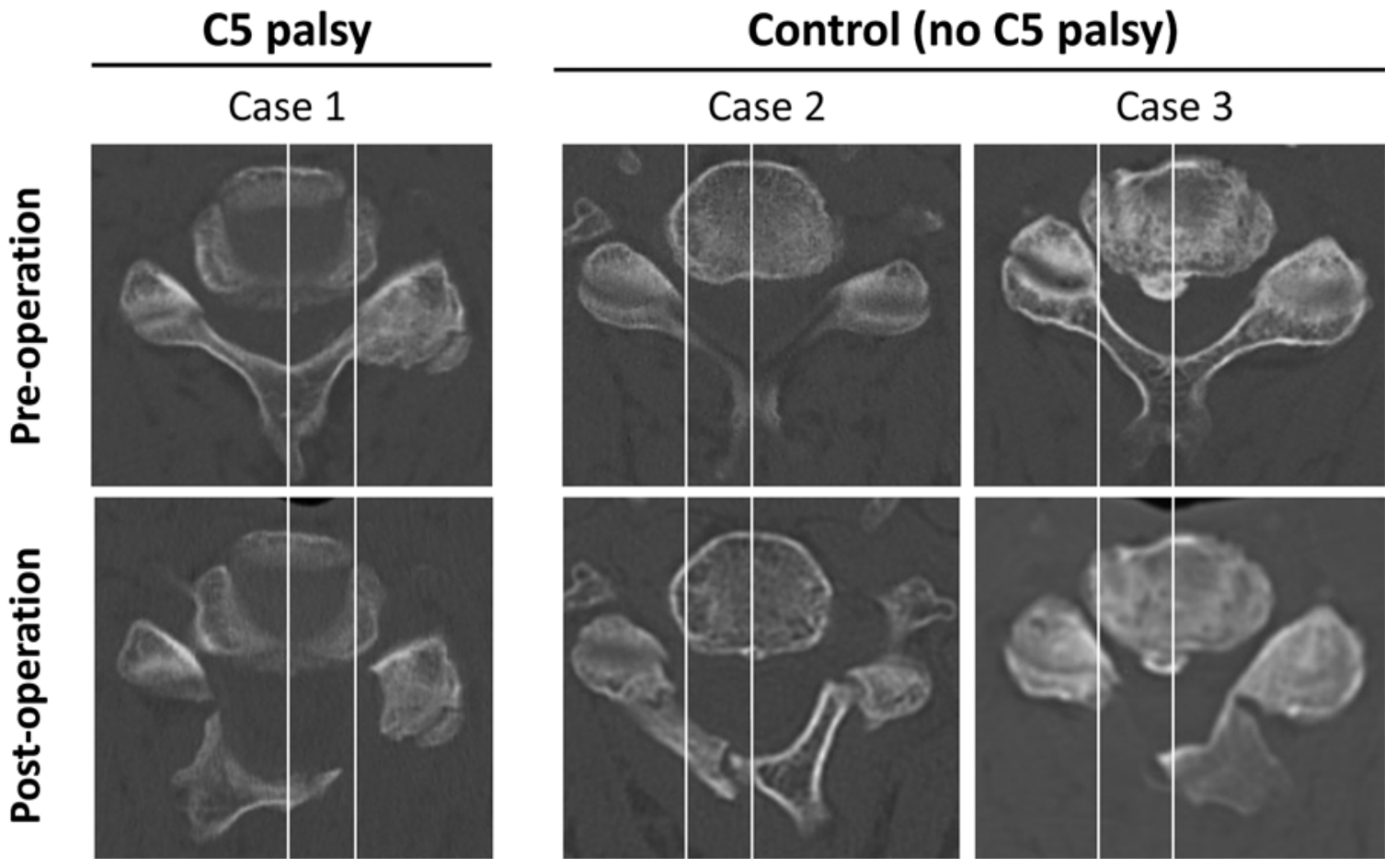

FIG. 3. Representative cases of patients after undergoing cervical laminoplasty: case 1 with C5 palsy and cases 2 and 3 without C5 palsy. Case 1: The position of the bony gutter and width of the C5 intervertebral foramen were $112.8 \%$ (wide) and $2.2 \mathrm{~mm}$ (narrow), respectively. Case 2: The position of the bony gutter was $101.8 \%$ (wide), but the width of the C5 intervertebral foramen was $3.1 \mathrm{~mm}$ (not narrow). Case 3: The width of the C5 intervertebral foramen was $1.8 \mathrm{~mm}$ (narrow), but the position of the bony gutter was $83.6 \%$ (not wide).

tained at $15^{\circ}-30^{\circ}$ to reduce the incidence of $\mathrm{C} 5$ palsy by preventing excessive posterior shift of the spinal cord..$^{32}$ However, in our patients, the spinal canal expansion rate was not associated with C5 palsy.

A number of articles have described a relationship between $\mathrm{C} 5$ palsy and preexisting $\mathrm{C} 4-5$ foraminal stenosis. ${ }^{7,11,14}$ One report found a higher risk for C5 palsy when the $\mathrm{C} 4-5$ foraminal diameter was $<2.7 \mathrm{~mm} .{ }^{17}$ In a retrospective study of 1858 patients who underwent cervical laminoplasty, the C5 intervertebral foramen was significantly smaller and the anterior protrusion of the C5 superior articular process was significantly greater in patients with C5 palsy. ${ }^{11}$ In our study, there was also a significant difference in the C5 intervertebral foramen width on the open side between patients with $(2.1 \mathrm{~mm})$ and without $(3.3 \mathrm{~mm}) \mathrm{C} 5$ palsy, but the anterior protrusion of the C5 superior articular process did not differ. A prophylactic combined foraminotomy has been proposed to prevent these mechanical effects, based on the incidences of C5 palsy after cervical laminoplasty: $0 \%,{ }^{23} 0.6 \%,{ }^{16}$ and $1.4 \%{ }^{15}$ with foraminotomy and $8.1 \%, 4.0 \%$, and $6.4 \%$ without foraminotomy. However, as shown in our representative cases, the width of the C5 intervertebral foramen was a risk factor, but was not essential, for the development of C5 palsy, since many patients without C5 palsy had a narrow C5 intervertebral foramen. Therefore, we suggest that a prophylactic combined foraminotomy is an unnecessary, invasive procedure that is not needed to prevent cervical nerve root dysfunction.
To obtain sufficient decompression of the spinal cord by laminoplasty, the gutter must be made sufficiently lateral to the spinal cord edges due to the thickness of the laminae. ${ }^{12}$ A narrower laminectomy trough width may prevent the spinal cord from shifting excessively, thus reducing the incidence of C5 palsy, ${ }^{21}$ since kinking of the C5 root due to an excessively lateral bony gutter might occur. ${ }^{22,31} \mathrm{In}$ our study, the mean position of the bony gutter in C5 palsy (group P) was $>100 \%$ (103.2\%), compared to $85.4 \%$ in no C5 palsy (group N). Our results indicated that drilling the bony gutter beyond the most medial part of the $\mathrm{C} 5$ facet joint is strongly associated with the incidence of C5 palsy. Another recent study showed that functional recovery can be expected in cases involving a laminectomy only $3.2 \pm$ $1.7 \mathrm{~mm}$ wider than the spinal cord width, and this decompression width may prevent an excessive posterior shift of the spinal cord. Use of these procedures has reduced the incidence of C5 palsy from $9.2 \%$ to $1.2 \% .^{20}$

Our results indicated that the spinal cord occupied only $62.4 \%$ of the spinal canal and that the distance between the lateral side of the spinal cord and the most medial part of the facet joint was $4.2 \pm 1.5 \mathrm{~mm}$. It is dangerous to choose the bony gutter width based on preoperative CT findings because the bony gutter is made using a high-speed drill in an inclined manner, but our results suggest that the best drilling starting point is about half a ball tip of the highspeed burr inward from the medial line of the facet joint (Fig. 4A). This procedure might permit sufficient decompression of the spinal cord without making an excessively 
A

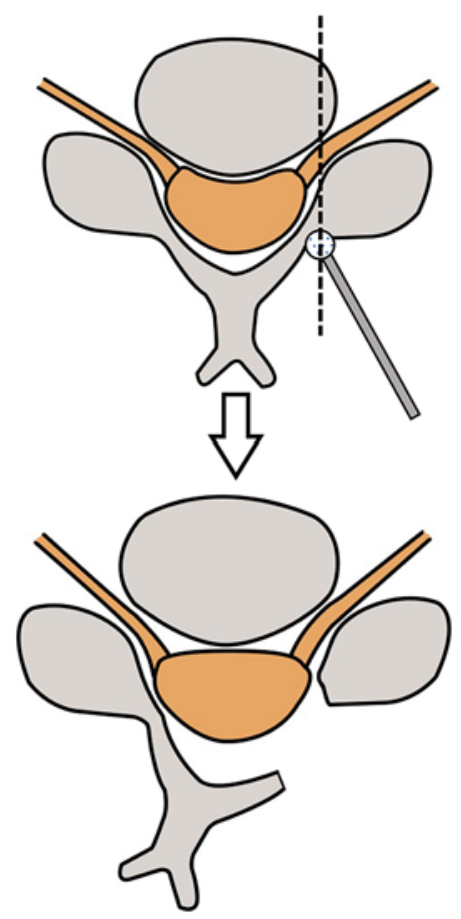

B

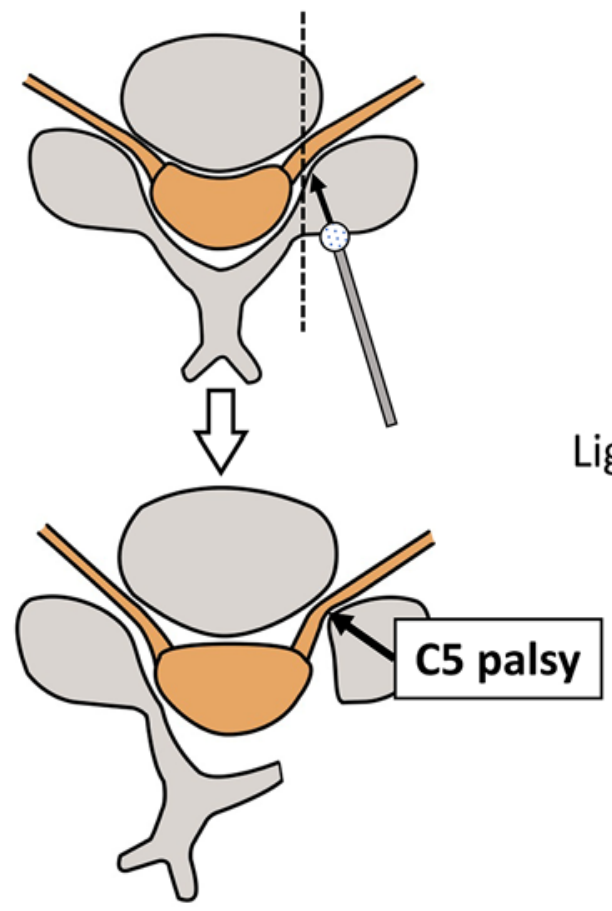

C

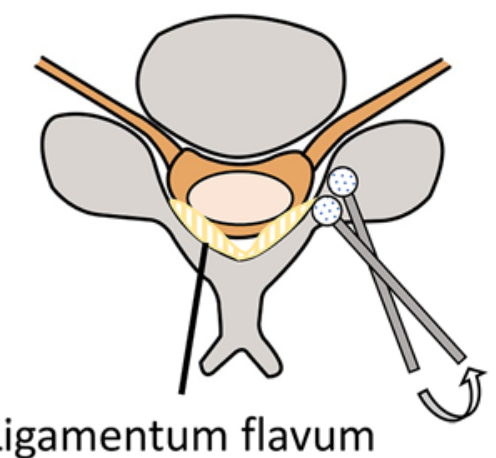

FIG. 4. Pathomechanism of and countermeasures for C5 palsy after cervical open-door laminoplasty. A: To achieve sufficient decompression of the spinal cord without making an excessively lateral bony gutter, the drill starting point is about half a ball tip of the high-speed burr inward from the medial line of the facet joint. B: An excessively lateral bony gutter beyond the most medial part of the $\mathrm{C} 5$ facet joint might be strongly associated with $\mathrm{C} 5$ nerve root kinking at the intervertebral foramen and may be the cause of C5 palsy. C: The ligamentum flavum is an important landmark with which to prevent making an excessively lateral bony gutter intraoperatively. In a case in which the ligamentum flavum cannot be identified, a high-speed burr should be turned to the inside to prevent C5 palsy. Figure is available in color online only.

lateral bony gutter beyond the most medial part of the $\mathrm{C} 5$ facet joint. An excessively lateral bony gutter (drilling the bony gutter beyond the most medial part of the $\mathrm{C} 5$ facet joint) might be a cause of C5 root kinking (Fig. 4B). Some reports have shown that the posterior shift of the spinal cord after laminoplasty was significantly greater in patients without clinical signs of palsy $(3.62 \mathrm{vs} 2.17 \mathrm{~mm}){ }^{2}$ In our study, the spinal canal expansion rate and posterior shift of the spinal cord at C4-5 were high ( 4.3 and $4.2 \mathrm{~mm}$ in patients with and without C5 palsy, respectively), but these parameters were not associated with the incidence of C5 palsy.

While making lateral gutters, the heat of friction with a high-speed burr may cause thermal injury to the nerve root, ${ }^{10,11}$ and the incidence of upper limb palsy significantly decreased from $9.5 \%$ to $4.0 \%$ using irrigation with chilled saline during bone drilling. ${ }^{27}$ In our study, the operating time tended to be longer in patients with $\mathrm{C} 5$ palsy (group P: 149.9 minutes) than in those without C5 palsy (group N: 130.0 minutes). Making an excessively lateral bony gutter beyond the medial line of the $\mathrm{C} 5$ facet joint might be time consuming and could increase the risk of heat-induced injury; therefore, this might be a risk factor for C5 palsy and might also be one of the reasons why C5 palsy occurred on the open side in all cases of this study.

Our results allow a proposal of countermeasures to pre- vent C5 palsy. If the bony gutter is made excessively lateral in patients with a narrow $\mathrm{C} 5$ intervertebral foramen, kinking of the $\mathrm{C} 5$ root could occur. This pathomechanism might be the main reason why C5 palsy occurs after cervical laminoplasty. The incidence of C5 palsy may be reduced by making the bony gutter of adequate width, with particularly careful consideration in cases involving a narrow C5 intervertebral foramen. It is important to confirm the medial line of the $\mathrm{C} 5$ facet joint on preoperative CT scans, especially in patients with severe spondylotic changes. During surgery, the ligamentum flavum can be used to detect the medial line of the facet joint because, anatomically, the capsular portion is absent above the midcervical level ${ }^{26}$ If the bony gutter is made excessively lateral on the open side, the ligamentum flavum does not appear at the expected depth. To prevent occurrence of C5 palsy, a high-speed burr should be started from inside the facet joint and manipulated in a direction that allows identification of the ligamentum flavum, which is an important anatomical landmark in the cervical spine for making an appropriate bony gutter (Fig. 4C). In a case that involves a bony gutter of an adequate width, the spinal canal expansion rate and posterior shift of the spinal cord may be less important, and a prophylactic combined foraminotomy is not needed. To confirm our hypothesis for the prevention of C5 palsy, a prospective study is required to determine 
whether changing the position of the bony gutter decreases the incidence of C5 palsy.

This study has certain limitations, including its retrospective, single-center design and the small number of patients. Despite these limitations, we believe that our findings provide important insights and guidance on surgical and clinical management for the prevention of C5 palsy after cervical open-door laminoplasty.

\section{Conclusions}

Clinical and radiological findings were evaluated in patients with C5 palsy after cervical laminoplasty. The width of the C5 intervertebral foramen was narrower and the position of the bony gutter was wider in patients with C5 palsy. Cervical alignment, spinal canal expansion rate, anterior protrusion of the C5 superior articular process, and posterior shift of the spinal cord were not significantly different in patients with and without C5 palsy. Making an excessive lateral bony gutter in patients with a narrow C5 intervertebral foramen might have a central role in the pathomechanism of postoperative C5 palsy. It is important to confirm the medial line of the facet joint on preoperative CT scans, especially in patients with severe spondylotic changes. To prevent the occurrence of C5 palsy, a highspeed burr should be started from inside the facet joint and manipulated in a direction that allows identification of the ligamentum flavum, which is an important anatomical landmark in the cervical spine for making an appropriate bony gutter.

\section{References}

1. Alleyne CH Jr, Cawley CM, Barrow DL, Bonner GD: Microsurgical anatomy of the dorsal cervical nerve roots and the cervical dorsal root ganglion/ventral root complexes. Surg Neurol 50:213-218, 1998

2. Baba S, Ikuta K, Ikeuchi H, Shiraki M, Komiya N, Kitamura $\mathrm{T}$, et al: Risk factor analysis for C5 palsy after double-door laminoplasty for cervical spondylotic myelopathy. Asian Spine J 10:298-308, 2016

3. Chen Y, Chen D, Wang X, Guo Y, He Z: C5 palsy after laminectomy and posterior cervical fixation for ossification of posterior longitudinal ligament. J Spinal Disord Tech 20:533-535, 2007

4. Chiba K, Ogawa Y, Ishii K, Takaishi H, Nakamura M, Maruiwa H, et al: Long-term results of expansive open-door laminoplasty for cervical myelopathy-average 14-year follow-up study. Spine (Phila Pa 1976) 31:2998-3005, 2006

5. Chiba K, Toyama Y, Matsumoto M, Maruiwa H, Watanabe M, Hirabayashi K: Segmental motor paralysis after expansive open-door laminoplasty. Spine (Phila Pa 1976) 27:21082115, 2002

6. Cho SK, Kim JS, Overley SC, Merrill RK: Cervical laminoplasty: indications, surgical considerations, and clinical outcomes. J Am Acad Orthop Surg 26:e142-e152, 2018

7. Gu Y, Cao P, Gao R, Tian Y, Liang L, Wang C, et al: Incidence and risk factors of C5 palsy following posterior cervical decompression: a systematic review. PLoS One 9:e101933, 2014

8. Hatta Y, Shiraishi T, Hase H, Yato Y, Ueda S, Mikami Y, et al: Is posterior spinal cord shifting by extensive posterior decompression clinically significant for multisegmental cervical spondylotic myelopathy? Spine (Phila Pa 1976) 30:2414-2419, 2005

9. Hirabayashi S, Kitagawa T, Yamamoto I, Yamada K, Kawano
H: Postoperative C5 palsy: conjectured causes and effective countermeasures. Spine Surg Relat Res 3:12-16, 2018

10. Hosono N, Miwa T, Mukai Y, Takenaka S, Makino T, Fuji T: Potential risk of thermal damage to cervical nerve roots by a high-speed drill. J Bone Joint Surg Br 91:1541-1544, 2009

11. Imagama S, Matsuyama Y, Yukawa Y, Kawakami N, Kamiya M, Kanemura T, et al: C5 palsy after cervical laminoplasty: a multicentre study. J Bone Joint Surg Br 92:393-400, 2010

12. Itoh T, Tsuji H: Technical improvements and results of laminoplasty for compressive myelopathy in the cervical spine. Spine (Phila Pa 1976) 10:729-736, 1985

13. Kanda Y: Investigation of the freely available easy-to-use software 'EZR' for medical statistics. Bone Marrow Transplant 48:452-458, 2013

14. Katsumi K, Yamazaki A, Watanabe K, Ohashi M, Shoji H: Analysis of C5 palsy after cervical open-door laminoplasty: relationship between C5 palsy and foraminal stenosis. J Spinal Disord Tech 26:177-182, 2013

15. Katsumi K, Yamazaki A, Watanabe K, Ohashi M, Shoji H: Can prophylactic bilateral C4/C5 foraminotomy prevent postoperative $\mathrm{C} 5$ palsy after open-door laminoplasty?: a prospective study. Spine (Phila Pa 1976) 37:748-754, 2012

16. Komagata M, Nishiyama M, Endo K, Ikegami H, Tanaka S, Imakiire A: Prophylaxis of C5 palsy after cervical expansive laminoplasty by bilateral partial foraminotomy. Spine $\mathbf{J}$ 4:650-655, 2004

17. Kurakawa T, Miyamoto H, Kaneyama S, Sumi M, Uno K: C5 nerve palsy after posterior reconstruction surgery: predictive risk factors of the incidence and critical range of correction for kyphosis. Eur Spine J 25:2060-2067, 2016

18. Nakajima H, Watanabe S, Honjoh K, Kitade I, Sugita D, Matsumine A: Long-term outcome of anterior cervical decompression with fusion for cervical ossification of posterior longitudinal ligament including postsurgical remnant ossified spinal lesion. Spine (Phila Pa 1976) 44:E1452-E1460, 2019

19. Nakashima H, Imagama S, Yukawa Y, Kanemura T, Kamiya M, Yanase M, et al: Multivariate analysis of C-5 palsy incidence after cervical posterior fusion with instrumentation. J Neurosurg Spine 17:103-110, 2012

20. Nori S, Aoyama R, Ninomiya K, Yamane J, Kitamura K, Ueda S, et al: Cervical laminectomy of limited width prevents postoperative C5 palsy: a multivariate analysis of 263 muscle-preserving posterior decompression cases. Eur Spine J 26:2393-2403, 2017

21. Radcliff KE, Limthongkul W, Kepler CK, Sidhu GD, Anderson DG, Rihn JA, et al: Cervical laminectomy width and spinal cord drift are risk factors for postoperative C5 palsy. J Spinal Disord Tech 27:86-92, 2014

22. Sakaura H, Hosono N, Mukai Y, Ishii T, Yoshikawa H: C5 palsy after decompression surgery for cervical myelopathy: review of the literature. Spine (Phila Pa 1976) 28:24472451,2003

23. Sasai K, Saito T, Akagi S, Kato I, Ohnari H, Iida H: Preventing C5 palsy after laminoplasty. Spine (Phila Pa 1976) 28:1972-1977, 2003

24. Shinomiya K, Okawa A, Nakao K, Mochida K, Haro H, Sato $\mathrm{T}$, et al: Morphology of C5 ventral nerve rootlets as part of dissociated motor loss of deltoid muscle. Spine (Phila Pa 1976) 19:2501-2504, 1994

25. Shou F, Li Z, Wang H, Yan C, Liu Q, Xiao C: Prevalence of C5 nerve root palsy after cervical decompressive surgery: a meta-analysis. Eur Spine J 24:2724-2734, 2015

26. Takahashi T, Hanakita J, Minami M: Pathophysiology of calcification and ossification of the ligamentum flavum in the cervical spine. Neurosurg Clin N Am 29:47-54, 2018

27. Takenaka S, Hosono N, Mukai Y, Tateishi K, Fuji T: Significant reduction in the incidence of C5 palsy after cervical laminoplasty using chilled irrigation water. Bone Joint J 98-B:117-124, 2016 
28. Tsuzuki N, Abe R, Saiki K, Okai K: Paralysis of the arm after posterior decompression of the cervical spinal cord. II. Analyses of clinical findings. Eur Spine J 2:197-202, 1993

29. Tsuzuki N, Abe R, Saiki K, Zhongshi L: Extradural tethering effect as one mechanism of radiculopathy complicating posterior decompression of the cervical spinal cord. Spine (Phila Pa 1976) 21:203-211, 1996

30. Uchida K, Nakajima H, Sato R, Kokubo Y, Yayama T, Kobayashi S, et al: Multivariate analysis of the neurological outcome of surgery for cervical compressive myelopathy. J Orthop Sci 10:564-573, 2005

31. Wu FL, Sun Y, Pan SF, Zhang L, Liu ZJ: Risk factors associated with upper extremity palsy after expansive open-door laminoplasty for cervical myelopathy. Spine J 14:909-915, 2014

32. Zhang H, Lu S, Sun T, Yadav SK: Effect of lamina open angles in expansion open-door laminoplasty on the clinical results in treating cervical spondylotic myelopathy. J Spinal Disord Tech 28:89-94, 2015

\section{Disclosures}

The authors report no conflict of interest concerning the materials or methods used in this study or the findings specified in this paper.

\section{Author Contributions}

Conception and design: Nakajima. Acquisition of data: Kuroda, Watanabe, Honjoh. Analysis and interpretation of data:

Nakajima, Kuroda. Drafting the article: Nakajima. Reviewed submitted version of manuscript: Watanabe, Honjoh, Matsumine. Approved the final version of the manuscript on behalf of all authors: Nakajima. Statistical analysis: Nakajima, Kuroda. Study supervision: Matsumine.

\section{Correspondence}

Hideaki Nakajima: University of Fukui Faculty of Medical Sciences, Fukui, Japan.nhideaki@u-fukui.ac.jp. 